\title{
Correction to: The limiting factors of oncolytic virus immunotherapy and the approaches to overcome them
}

\author{
Pei-Yang $\mathrm{Hu}^{1} \cdot$ Xiao-Ming Fan ${ }^{2} \cdot$ You-Ni Zhang ${ }^{1,3,4} \cdot$ Shi-Bing Wang ${ }^{3,4} \cdot$ Wei-Jie Wan ${ }^{5} \cdot$ Hong-Ying Pan $^{6}$. \\ Xiao-Zhou Mou ${ }^{3,4}$
}

Published online: 18 June 2021

(C) Springer-Verlag GmbH Germany, part of Springer Nature 2021

\section{Correction to: Applied Microbiology and Biotechnology (2020) 104:8231-8242 https://doi.org/10.1007/s00253-020-10802-w}

There is an error in the Introduction section of the original publication. The text "Two are against advanced melanoma, among which one was approved in the USA, Europe, and Australia based on a modified oncolytic herpes simplex virus (HSV) type 1 known as talimogene laherparepvec (T-VEC) and the other a reovirus sold under the name Rigvir commercialized in Latvia, Estonia, Poland, and Belarus (Alberts et al. 2016; Harrington et al. 2015)." should be replaced by: "Two are against advanced melanoma, among which one was approved in the USA, Europe, and Australia based on a modified oncolytic herpes simplex virus (HSV) type 1 known as talimogene laherparepvec (T-VEC) and the other an ECHO-7 virus sold under the name Rigvir and approved in Latvia, Georgia, Armenia and Uzbekistan (Alberts et al. 2016; Donina et al. 2015; Alberts et al. 2018)."

The online version of the original article can be found at https://doi.org/ $10.1007 / \mathrm{s} 00253-020-10802-\mathrm{w}$

Hong-Ying Pan hypanhz@139.com

$\triangle$ Xiao-Zhou Mou mouxz@zju.edu.cn

1 Department of Traumatology, Tiantai People's Hospital of Zhejiang Province (Tiantai Branch of Zhejiang People's Hospital),

Taizhou 317200, China

2 Department of Ultrasound, Zhejiang Provincial People's Hospital (People's Hospital of Hangzhou Medical College),

Hangzhou 310014, China

\section{References}

Alberts P, Olmane E, Brokāne L, Krastina Z, Romanovska M, Kupčs K, Isajevs S, Proboka G, Erdmanis R, Nazarovs J, Venskus D (2016) Long-term treatment with the oncolytic ECHO-7 virus Rigvir of a melanoma stage IV M1c patient, a small cell lung cancer stage IIIA patient, and a histiocytic sarcoma stage IV patient-three case reports. Acta Pathol Microbiol Immunol Scand 124(10):896-904. https:// doi.org/10.1111/apm. 12576

Alberts P, Tilgase A, Rasa A, Bandere K, Venskus D (2018) The advent of oncolytic virotherapy in oncology: the Rigvir ${ }^{\circledR}$ story. Eur J Pharmacol 837:117-126. https://doi.org/10.1016/j.ejphar.2018.08.042

Doniņa S, Strēle I, Proboka G, Auziņš J, Alberts P, Jonsson B, Venskus D, Muceniece A (2015) Adapted ECHO-7 virus Rigvir immunotherapy (oncolytic virotherapy) prolongs survival in melanoma patients after surgical excision of the tumour in a retrospective study. Melanoma Res 25(5):421-426. https://doi.org/10.1097/CMR. 0000000000000180

Publisher's note Springer Nature remains neutral with regard to jurisdictional claims in published maps and institutional affiliations.

Key Laboratory of Tumor Molecular Diagnosis and Individualized Medicine of Zhejiang Province, Zhejiang Provincial People's Hospital (People's Hospital of Hangzhou Medical College), Hangzhou 310014, China

4 Clinical Research Institute, Zhejiang Provincial People's Hospital (People's Hospital of Hangzhou Medical College), Hangzhou 310014, China

5 Shandong Xiandai University, Jinan 250104, China

6 Department of Infectious Diseases, Zhejiang Provincial People's Hospital (People's Hospital of Hangzhou Medical College), Hangzhou 310014, China 